\title{
PERTUMBUHAN DAN PATOGENISITAS BEBERAPA ISOLAT MUTAN Metarhizium anisopliae TERHADAP HAMA PENGHISAP POLONG (Riptortus linearis)
}

\section{GROWTH AND PATHOGENICITY OF Metarhizium anisopliae MUTANT ISOLATES ON POD SUCKING BUG (Riptortus linearis)}

\author{
Puji Astuti*, Yuyun Fitriana, Lestari Wibowo dan FX. Susilo \\ Program Studi Agroteknologi Fakultas Pertanian Universitas Lampung \\ JL. Prof. Dr. Soemantri Brojonegoro, No. 1 Bandar Lampung 35145 \\ *Email:puji.astuti412@yahoo.com
}

\begin{abstract}
Growth and pathogenicity of Metarhizium anisopliae mutant isolates on pod sucking bug (Riptortus linearis). This study aimed to determine the growth ability of Metarhizium anisopliae mutant (colony diameter, spore density, and viability) and the ability of M. anisopliae to cause mortality in pod sucking bug(Riptortus linearis). The study conducted at the Laboratory of Agricultural Biotechnology, Faculty of Agriculture, University of Lampung. The study began in December 2016-April 2017. M. anisopliae used in this study were isolate B wildtype (MYFT B), mutant M. anisopliae 1 (MYFT 1), mutant M. anisopliae 42 (MYFT 42), and M. mutant anisopliae 51 (MYFT 51). The results of this study indicated that the Myft $B$ isolate (wildtype) had the widest diameter $(5.50 \mathrm{~cm})$ with the highest spore density in the MYFT 42 mutant isolate (7.4000 108 spores / ml) and the highest viability in the MYFT 51 mutant isolate (96.75\%). MYFT 51 and MYFT 42 mutant isolates were able to cause $100 \%$ mortality of R. linearis and significantly higher compared to the MYFT 1 mutant isolates and wildtype MYFT B.
\end{abstract}

Keywords: Metarhizium anisopliae, pathogenicity, growth, Riptortus linearis

\section{ABSTRAK}

Pertumbuhan dan patogenisitas beberapa isolat mutan Metarhizium anisopliae terhadap hama penghisap polong (Riptortus linearis). Penelitian ini bertujuan untuk mengetahui kemampuan pertumbuhan (diameter koloni, kerapatan spora, dan viabilitas) mutan jamur Metarhizium anisopliae dan mengetahui kemampuan jamur $M$. anisopliae dalam menyebabkan mortalitas hama pengisap polong (Riptortus linearis). Penelitian dilakukan di Laboratorium Bioteknologi Pertanian Fakultas Pertanian Universitas Lampung. Penelitian dimulai bulan Desember 2016 - April 2017. M. anisopliae yang digunakan pada penelitian ini yaitu isolat B wildtype (MYFT B), mutan M. anisopliae 1 (MYFT 1), mutan M. anisopliae 42 (MYFT 42), dan mutan M. anisopliae 51 (MYFT 51). Hasil penelitian ini menunjukkan bahwa isolat Myft B (wildtype) memiliki diameter terlebar $(5,50 \mathrm{~cm})$ dengan kerapatan spora tertinggi pada isolat mutan MYFT $42\left(7,4000 \times 10^{8} \mathrm{spora} / \mathrm{ml}\right)$ dan viabilitas tertinggi pada isolat mutan MYFT 51 (96,750\%). Isolat mutan MYFT 51 dan MYFT 42 mampu menyebabkan mortalitas $R$. linearis sebesar 100\% dan secara nyata lebih tinggi dibandingkan dengan isolat mutan MYFT 1 dan wildtype MYFT B.

Kata Kunci : Metarhizium anisopliae, patogenisitas, pertumbuhan, Riptortus linearis. 


\section{PENDAHULUAN}

Kacang-kacangan merupakan tanaman sayuran semusim yang banyak dimanfaatkan oleh masyarakat Indonesia. Beragam jenis tanaman kacang-kacangan yang dapat ditemukan dengan mudah di Indonesia, antara lain kacang panjang, kedelai, kacang merah, kacang hijau dan lain-lain.Petani yang membudidayakan tanaman kacang-kacangan tersebar di dataran tinggi dan rendah.

Usaha budidaya kacang-kacangan di Indonesia masih mengalami kendala, salah satunya adalah permasalahan hama. Terdapat beberapa spesies hama yang mengisap atau perusak polong yaitu kepik penghisap polong (R.linearis F.), kepik hijau (Nezara viridula) dan kepik piezodorus (Piezodorus rubrofasciatus). Diantara ketiga hama tersebut, Penghisap polong (R. linearis) mempunyai daerah penyerangan yang paling luas dan sangat merugikan (Asadi, 2009). Kerugian ini terjadi karena serangganya secara langsung merusak biji sehingga menurunkan produksi dan kualitas biji. Akibat serangan hama ini petani dapat mengalami gagal panen jika tidak dikendalikan (Marwoto, 2012).

Upaya pengendalian hama pengisap polong kedelai terus dikembangkan, antara lain pemanfaatan agensia hayati (Tengkano et al., 1992). Salah satu agensia hayati yang banyak dikembangkan adalah jamur entomopatogen. Keunggulan penggunaan jamur entomopatogen sebagai pengendali populasi serangga hama adalah mampu membentuk spora yang tahan terhadap pengaruh lingkungan. Salah satu jamur entomopatogen yang banyak dimanfaatkan dalam pengendalian secara hayati adalah jamur M. anisopliae (Rosmayuningsih et al., 2014).

Infeksi jamur $M$. anisopliae dapat menyebabkan kelumpuhan otot serangga (Samuels, 1998). M. anisopliae telah banyak digunakan untuk mengendalikan berbagai jenis hama tanaman, antara lain kumbang gandum (Anisopliae austriaca), hama tebu (Cleanus punctiventris), kumbang tanduk (Oryctes rhinocheros), hama bubuk kopi, termasuk juga hama penghisap buah kakao (Helopeltisspp.) (Gunapradangga, 2014).

Penelitian tentang mutan dari jamur entomopatogen saat ini mulai banyak dilakukan. Mutan adalah organisme atau karakter genetik baru yang timbul atau dihasilkan karena adanya mutasi (Anonim, 2015). Mutan dari satu jenis entomopatogen dapat memiliki sifat unggul dalam kemampuan menginfeksi serangga inangnya. Metarhizium dalam bentuk mutan yang dihasilkan karna proses radiasi perlu diteliti apakah juga memilikikeunggulan.

Pada penelitian ini akan diamati pertumbuhan beberapa isolat mutan M. anisopliae dan mortalitas serangga uji akibat aplikasi beberapa isolat jamur mutan M.anisopliae. Mortalitas pada serangga uji menggambarkan patogenisitas dari jamur entomopatogen.

\section{BAHAN DAN METODE}

Bahan yang digunakan pada penelitian ini yaitu mutan dan wildtype M. anisopliae (Tabel 1), alkohol, kacang panjang, aquades, kentang, agar batang, gula, kertas label, nimfa $R$. linearis instar 3, sedangkan alat 
yang digunakan pada penelitian ini yaitu stoples plastik untuk pemeliharaan serangga uji, sprayer, cawan petri, karet gelang, jarum ose, laminar air flow (LAF), mikroskop, spatula, tabung reaksi, erlenmeyer, haemocytometer, drigalsky, bunsen, autoklaf, shaker, mikropipet, borgabus, stoples, timbangan, kompor, ketas label, kain kasa, karet, tisu, nampan, dan kuas.

Penelitian ini terdiri dari 2 set percobaan. Percobaan yang pertama yaitu uji pertumbuhan $M$. anisopliae mutan dan wildtype secara in vitro dalam media PDA.

Penelitian ini menggunakan Rancangan Acak Lengkap (RAL) dengan empat perlakuan yang diulang sebanyak empat kali. Variabel yang diamati yaitu pertumbuhan koloni M. anisopliae, kerapatan dan viabilitas spora M. anisopliae. Perlakuannya adalah aplikasi suspensi MYFT B, MYFT 1, MYFT 42 dan MYFT 51 (Tabel 1).

Set percobaan yang kedua adalah uji patogenesitas mutan dan wildtype $M$. anisopliae terhadap $R$. linearis. Percobaan ini menggunakan Rancangan Acak Kelompok (RAK), dengan 5 perlakuan dan diulang 4 kali, sehingga terdapat 20 unit percobaan. Dalam 1 unit percobaan menggunakan 10 ekor serangga. Perlakuan yang digunakan dalam penelitian ini adalah sebagai berikut :

1. MYFT B: Aplikasi suspensi jamur wildtype $M$. anispoliae $\mathrm{B}$ dengan kerapatan spora $\mathrm{n} \times 10^{8}$ spora $/ \mathrm{ml}$.

2. MYFT 1: Aplikasi suspensi jamur mutan $M$. anisopliae 1 dengan kerapatan spora $\mathrm{n} \times 10^{8}$ spora/ $\mathrm{ml}$.

3. MYFT 42 : Aplikasi suspensi jamur mutan $M$. anisopliae 42 dengan kerapatan spora $\mathrm{n} \times 10^{8}$ spora $/ \mathrm{ml}$.

4.MYFT 51: Aplikasi suspensi jamur mutan $M$. anisopliae 51 dengan kerapatan spora $\mathrm{n} \times 10^{8}$ $\mathrm{spora} / \mathrm{ml}$.

5.Kontrol ( $0,1 \%$ Tween 80$)$.

Variabel yang diamati pada penelitian ini antara lain pertumbuhan jamur M. anisopliae wildtype dan mutan. Pengamatan pertumbuhan jamur dilakukan cara mengukur diameter koloni jamur secara vertikal dan horizontal lalu dijumlahkan dan dibagi dengan 2. Pengamatan dilakukan setiap hari dimulai 1 hari setelah inokulasi selama 14 hari.

Selanjutnya yaitu kerapatan spora dengan menggunakan suspensi spora yang telah didapatkan lalu

Tabel 1. Isolat yang digunakan dalam penelitian

\begin{tabular}{lcl}
\hline \multicolumn{1}{c}{ Isolat } & Kode & \multicolumn{1}{c}{ Asal isolate } \\
\hline Metarhizium anisopliae B (wild type) & MYFT B & Larva Heptophylla picea dan larva kumbang dari Shizuoka \\
Mutan Metarhizium anisopliae 1 & MYFT 1 & Irradiasi ion-beam (100) Gy \\
Mutan Metarhizium anisopliae 42 & MYFT 42 & Irradiasi Gamma-ray (100) Gy \\
Mutan Metarhizium anisopliae 51 & MYFT 51 & Irradiasi Gamma-ray (100) Gy \\
\hline
\end{tabular}


diteteskan pada haemocytometer, dilakukan pengenceran $10^{8}$ setelah itu diambil $1 \mathrm{ml}$ dari masingmasing perlakuan tersebut dan diteteskan pada haemocytometer. Kemudian dilakukan pengamatan di bawah mikroskop. Penghitungan kerapatan spora dilakukan dengan cara memilih 3 kotak perhitungan, tiap kotak tersebut dihitung dan dirata-rata nilainya.

Kerapatan spora dihitung dengan menggunakan rumus sebagai berikut :

$$
\mathrm{S}=\mathrm{R} \times \mathrm{K} \times \mathrm{F}
$$

Keterangan :

$\mathrm{S}=$ Jumlah spora $/ \mathrm{ml}$

$\mathrm{R}=$ Jumlah rata-rata spora pada 5 kotak sedang haemocytometer

$\mathrm{K}=$ Konstanta koefisien alat $(2,5 \times 10)$

$\mathrm{F}=$ Faktor Pengenceran yang digunakan

Selanjutnya dilakukan penghitungan viabilitas spora dengan cara suspensi sampel yang telah diamati kerapatan sporanya kemudian diteteskan sebanyak 25 $\mu 1$ pada media PSA dan diinkubasi selama 16 jam. Pengamatan viabilitas dilakukan di bawah mikroskop. Viabilitas spora dihitung apabila ada spora yang mulai berkecambah. Spora dikatakan berkecambah apabila panjang ukuran spora bertambah. Viabilitas spora dihitung menggunakan rumus sebagai berikut :

$$
\mathrm{V}=\frac{g+u}{g} \times 100 \%
$$

Keterangan :

$\mathrm{V}=$ Perkecambahan spora (viabilitas)

$\mathrm{g}=$ Jumlah spora yang berkecambah

$\mathrm{u}=$ Jumlah spora yang tidak berkec ambah

Pengamatan mortalitas hama $R$. linearis dilakukan setiap hari selama 7 hsa sampai nimfa menjadi imago dan sampai serangga uji mati, baik yang diberi perlakuan semprot atau kontrol. Nimfa $R$. linearis yang diduga terinfeksi jamur M. anisopliae dipisahkan dalam wadah untuk dilembapkan dengan cara dimasukkan ke dalam cawan petri yang sudah dilapisi tisu basah, kemudian diamati di bawah mikroskop untuk memastikan mortalitas nimfa $R$. linearis disebabkan oleh larutan jamur M. anisopliae. untuk menghitung mortalitas nimfa dapat dilakukan perhitungan dengan rumus sebagai berikut:

$$
\text { Mortalitas (\%) }=\frac{\text { Jumlah nimfa yang mati }}{\text { Jumlah nimfa uji }} \times 100 \%
$$

\begin{tabular}{|c|c|c|c|}
\hline Perlakuan & Diameter koloni $(\mathrm{cm})$ & Kerapatan spora (x 108/ml) & Viabilitas spora (100\%) \\
\hline MYFT B & $5,50 \mathrm{a}$ & $1,6750 \mathrm{~b}$ & $88,250 \mathrm{ab}$ \\
\hline MYFT 1 & $4,25 \mathrm{~b}$ & $4,1500 \mathrm{ab}$ & $83,500 \mathrm{ab}$ \\
\hline MYFT 51 & $3,00 \mathrm{c}$ & $5,7750 \mathrm{ab}$ & $96,750 \mathrm{a}$ \\
\hline MYFT 42 & $3,75 \mathrm{bc}$ & $7,4000 \mathrm{a}$ & $80,250 \mathrm{~b}$ \\
\hline Fhit & $11,8^{*}$ & $4,44 *$ & $2,32 *$ \\
\hline$\overline{\mathrm{BNT}}(0,05)$ & 1,07 & 4,07 & 16,54 \\
\hline
\end{tabular}

Tabel 2. Pertumbuhan jamur M. anisopliae isolat wildtype MYFT B, dan isolat mutan MYFT 1, MYFT 51 dan MYFT 42. 


\section{HASIL DAN PEMBAHASAN}

Hasil penelitian memperlihatkan bahwajamur M. anisopliae isolat wildtype MYFT B danjamur $M$. anisopliae isolat mutan MYFT 1, MYFT 51, MYFT 42 mampu tumbuh dan berkembang dengan normal. Jamur M. anisopliae isolat mutan MYFT 42 menghasilkan spora yang lebih banyak dibandingkan jamur M. anisopliae isolat mutan MYFT 1, MYFT 51 dan isolat wildtype MYFT $\mathrm{B}$, namun daya kecambah isolat mutanMYFT 42 tidak lebih tinggi dari ke tiga isolat tersebut. Data pertumbuhan jamur $M$. anisopliae tertera pada Tabel 2 .

\section{Diameter Koloni}

Diameter koloni jamur M. anisopliae berbeda nyata antar isolat. Diameter koloni tertinggi ditunjukkan oleh jamur M. anisopliae isolat wildtype MYFT B yaitu sebesar $5,50 \mathrm{~cm}$. Jamur M. anisopliae isolat wildtype MYFT B mampu tumbuh dengan baik dan secara nyata memiliki diameter koloni tertinggi dibandingkan ketiga isolat jamur lainnya. Jamur $M$. anisopliae isolat mutan MYFT 51 memiliki diameter terendah yaitu sebesar $3,00 \mathrm{~cm}$.

\section{Kerapatan Spora}

Jamur M. anisopliae memiliki kerapatan spora yang berbeda antar isolat. Jamur M. anisopliae isolat mutan MYFT 42 mempunyai kerapatan spora tertinggi yaitu sebesar 7,4000x $10^{8} \mathrm{spora} / \mathrm{ml}$. Jamur $M$. anisopliae isolat mutan MYFT 42 tidak berbeda nyata dengan jamur M. anisopliae isolat mutan MYFT 1 dan MYFT 51 yaitu sebesar 4,1500 x $10^{8} \mathrm{spora} / \mathrm{ml}$ dan $5,7750 \times 10^{8} \mathrm{spora} / \mathrm{ml}$. Kerapatan spora terendah didapatkan jamur M. anisopliae isolat wildtype
MYFT B yang hanya mencapai $1,6750 \times 10^{8} \mathrm{spora} / \mathrm{ml}$

\section{Viabilitas Spora}

Viabilitas spora jamur M. anisopliae berbeda antar isolat. Viabilitas Spora M. anisopliae yang memiliki daya berkecambah paling tinggi yaitu jamurM. anisopliae isolat mutan MYFT 51 yang mencapai 96,7\%, dan berbeda nyata dengan jamur $M$. anisopliae isolat mutan MYFT 42 dengan perkecambahan spora sebesar 80,2\%. Jamur dengan nilai perkecambahan spora yang tidak berbeda nyata dengan jamur M. anisopliae isolat mutan MYFT 51 adalah jamur M. anisopliae isolat wildtype MYFT B dan jamur M. anisopliae isolat mutan MYFT 1 dengan kisaran perkecambahan sebesar $88,2 \%$ dan $83,5 \%$. Perkecambahan spora paling rendah diperoleh pada jamur M. anisopliae isolat mutan MYFT 42 yaitu sebesar 80,2\%. Baik jamur mutan maupun wildtype mampu berkecambah dengan baik dimana daya kecambah lebih dari $80 \%$.

\section{Pengaruh Aplikasi Jamur Metarizium anisopliae terhadap Riptortus linearis}

Jamur mutan dan wildtype M. anisopliae memiliki kemampuan yang berbeda. Berdasarkan Tabel 3, dapat dilihat bahwa jamur M. anisopliae mempunyai kemampuan yang berbeda dalam membunuh serangga R. linearis. M. anisopliae yang memiliki kemampuan menyebabkan mortalitas paling tinggi yaitu jamur $M$. anisopliae isolat mutan MYFT 51 dan MYFT 42 yang mencapai 100\% hingga hari ke 7 setelah aplikasi, namun jamur M. anisopliae isolat wildtype MYFT 51 yang lebih dulu dapat menyebabkan kematian hama $R$. linearis. Kemampuan membunuh jamur 
Tabel 3. Mortalitas R. linearis (\%) setelah diaplikasi jamur M.anisopliae 7 HSA

\begin{tabular}{|c|c|}
\hline Perlakuan & Mortalitas R. linearis (\%) \\
\hline MYFT B & $87,50 \mathrm{c}$ \\
\hline MYFT 1 & $92,50 \mathrm{~b}$ \\
\hline MYFT 51 & $100,00 \mathrm{a}$ \\
\hline MYFT 42 & $100,00 \mathrm{a}$ \\
\hline Fhit & $598,25^{*}$ \\
\hline BNT $(0,05)$ & 2,98 \\
\hline
\end{tabular}

M. anisopliae isolat mutan MYFT 51 tidak berbeda nyata dengan jamur $M$. anisopliae isolat mutanMYFT 42, tetapi berbeda nyata dengan jamur M. anisopliae isolat wildtype MYFT B dan jamur M. anisopliae isolat mutan MYFT 1 dengan mortalitas sebesar $87,50 \%$ dan $92,50 \%$. Mortalitas paling rendah dihasilkan oleh jamur M. anisopliae isolat wildtype MYFT B yaitu mencapai 87,50\%.

Hasil penelitian memperlihatkan bahwa jamur M. anisopliae isolat wildtype MYFT B dan jamur $M$. anisopliae isolat mutan MYFT 1, MYFT 51, MYFT 42 mampu tumbuh dan berkembang dengan normal. Isolat mutan MYFT 42 menghasilkan spora yang lebih banyak dibandingkan jamur M. anisopliae isolat mutan MYFT 1, MYFT 51 dan isolat wildtype MYFT B, daya kecambah isolat mutan MYFT 42 tidak lebih tinggi dari ke tiga isolat tersebut. Namun dengan demikian jumlah konidia yang tinggi atau rendah, tidak mempengaruhi jamur entomopatogen dalam membunuh hama sasaran.

\section{KESIMPULAN DAN SARAN}

Kesimpulan dari penelitian ini adalah pertumbuhan diameter koloni jamur Metarhizium anisopliae isolat wildtype MYFT B lebih tinggi dibandingkan dengan isolat mutan (MYFT 1, MYFT 51 dan MYFT 42), kerapatan spora jamur $M$. anisopliae isolat mutan MYFT 42 lebih tinggi dibandingkan dengan isolat wildtype MYFT B, dan viabilitas spora jamur M. anisopliae isolat wildtype MYFT B tidak berbeda nyata dengan isolat mutan (MYFT 1, MYFT 51 dan MYFT 42). Jamur $M$. anisopliae isolat mutan (MYFT 1, MYFT 51 dan MYFT 42) secara nyata mampu menyebabkan mortalitas lebih tinggi terhadap hama Riptortus linearis dibandingkan isolat wildtype MYFT B.

Berdasarkan hasil penelitian ini, penulis menyarankan Perlu adanya penelitian lebih lanjut tentang penggunaan isolat $M$. anisopliae ini dengan tingkat kerapatan spora yang berbeda-beda sehingga dapat diketahui konsentrasi kerapatan spora yang paling efektif dalam menginfeksi $R$. linearis.

\section{DAFTAR PUSTAKA}

Anonim. 2015. Pengertian Mutan.http:// biosend.blogspot.co.id/2015/10/pengertianmutan.html. Diakses 22 Januari 2017. 
Asadi. 2009. Identifikasi ketahanan sumber daya genetik kedelai terhadap hama pengisap polong. Buletin Plasma Nutfah.15(1): 2731.

Gunapradangga, A.2014.Metarhizium anisopliae. http://agrikencanaperkasa.com/ metarhizium-anisopliae/.Diakses $11 \mathrm{Mei}$ 2016.

Marwoto. 2012. Waspadai pengisap polong Riptortus pada kedelai di musim kem arau.http:// balitkabi.litbang.pertanian.go.id/kilaslitbang/1644- waspada-pengisap-polongriptortus-pada-kedelai-di-musimkemarau.pdf. Diakses 20 Agustus 2017.

Rosmayuningsih, A., B. T. Rahardjo., \& Rachmawati.2014. Patogenisitas jamur Metarhizium anisopliae terhadap hama kepinding tanah (Stibaropus molginus)
(Hemiptera:Cydnidae) dari beberapa formulasi. Jurnal Hama Penyakit Tanaman.2(2): 28-37.

Samuels, R.I.1998.Systematics morphology and physiology: A sensitive bioassay for dextruxins, cyciodepsipeptides from the culture filtrates of the entomopathonic fungus Metarhizium anisopliae (Metch.) Sorok.An. Soc. Entomol. 27(2): 229-235.

Tengkano, W.,Arifin, M., \&Tohir, A. M. 1992. Bioekologi, Serangan dan Pengendalian Hama Pengisap dan Penggerek Polong Kedelai. Dalam Marwoto, N. Saleh, Sunardi, \& A. Winarto (Ed.s). Risalah Lokakarya Pengendalian Hama Terpadu Tanaman Kedelai, Malang 8"10 Agustus 1991. Balai Penelitian Tanaman Pangan Malang. Hlm 117"153. 